\title{
Does acute toxicity testing tell us anything useful? Methyl isocyanate as a test case
}

In the hours after the tragedy at Bhopal was described in the newspapers and shown on television one imagines that nearly every toxicologist and occupational physician in the world must have reached for their favourite reference book and turned the pages to see what was known about the toxic effects of methyl isocyanate. Those with the necessary facilities, and particularly those concerned with the medical and scientific programmes that have followed the disaster, will no doubt also have run computer searches of published reports. All these diverse inquiries will have received the same answer: "not a lot!"

The only studies to have been reported widely indicate $\mathbf{L D}_{50}$ values after oral, inhalation, or skin exposure of rodents and guinea pigs. Some experience with handling this compound confirms the high level of irritancy to skin, eyes, and respiratory tract which would be expected, and a suitably low exposure limit has been defined by the American authorities. In respect of the amount of available information, methyl isocyanate resembles a large number of reactive and toxic materials that would not be given further consideration unless an accident or political controversy lends them an unexpected notoriety. There is a good reason for the limited study given to these materials-namely, the cost of more detailed investigations. A material which by its nature could never be used except as a chemical intermediate confined within a technically advanced chemical plant is obviously a less urgent case for study than one to which large numbers of people are exposed, perhaps without their knowledge or agreement, and where important long term effects such as carcinogenesis may be suspected. On the other hand, it is now required that some tests be performed on new compounds of this type, and it seems appropriate to ask, in the light of the experience with methyl isocyanate, whether we are getting value for money from this limited exercise.

One may perhaps begin by speculating as to whether any form of toxicological investigation could have warned of the potential for methyl isocyanate to cause the reported 2500 deaths in a single accident, or have helped the treatment and social support of the many thousand affected survivors. A major factor in the occurrence and outcome of the incident at Bhopal must have been the various engineering and social factors which have already received much attention in the popular press. It has been alleged that there were deficiencies (relative to recognised good practice and the standards legally required in developed countries) in the location, design, and maintenance of the plant. Safety systems and work practices are also said to have been ignored or treated with less than the appropriate degree of care. If more information on the toxicological effects of methyl isocyanate had been available, not only to the plant management (whom one must assume to have been aware of the potential problems to some degree), but also to the workers and public authorities, perhaps these omissions would not have occurred.

It may be worth considering how rare major disasters affecting chemical plants actually are. A recent article in Time magazine detailed several major incidents over the past 50 years, ${ }^{1}$ of which all, except Seveso and Bhopal, were actually fires or explosions rather than toxic chemical incidents-Flixborough and San Juan Ixhuatepec, for example. Apart from two pre-1939 explosions resulting from mis-handling ammonium nitrate fertiliser, all these fires involved fuels or petrochemical derived feedstocks, which tend to be used in much larger quantities than toxic or reactive chemicals. Although the Seveso incident was of great importance in alerting the world to the possibility of large scale accidents endangering life and property, the actual experience of human mortalitythat is, zero-and morbidity to date seems to be less severe than was feared might occur at the time of the incident. So it seems that the Bhopal incident is unique in scale and in the severity of its consequences. It has been known for many years that catastrophic consequences of accidents at chemical plants are sometimes possible, but provided that engineering controls and systems of work are applied they will be rare in developed countries. But events such as these have to be considered and, where possible, guarded against, in the same way as the extremely rare but disastrous compound failure catastrophes predicted in the nuclear industry. Also, these rare major events represent the extreme of a distribution in size and severity of industrial accidents involving chemicals, of which the less dramatic examples are much more common. It is also known that these smaller accidents are more common and have more severe consequences for a 
given scale of incident in developing countries compared with the Western industrial countries, where technical expertise and legislative control are more highly developed. With the increasing shift of industrial technology, particularly potentially hazardous chemical processes to developing countries, the prevalence of major accidents may well increase with severe consequences unless steps are taken to oppose this tendency.

We do not know at present whether there are specific features of the toxicity of methyl isocyanate that make it more dangerous than other reactive materials that damage the respiratory system, such as phosgene. Possible neurological effects in addition to the effects on lungs and eyes of survivors have been suggested, which may be supported in due course by animal toxicity data. In any event, a description of the effects of poisoning by this compound in terms of dose response for effects other than simply death would have helped both those responsible for treating affected people and those attempting to use epidemiological methods to explore and predict the outcome of the incident for the population as a whole. Important sublethal effects such as irritation of the respiratory tract, or the skin, may be investigated systematically without excessive expenditure of time or money, but in this and many other cases the data are reported by a single word, if at all. More detailed questions, such as the degree of similarity between human and animal responses, or the possibility of specific antidotes, would have depended on detailed biochemical studies which it is probably unrealistic to expect to have been done before the disaster.

There has been a considerable amount of criticism (some constructive, some not) of the $\mathrm{LD}_{50}$ test in its simplest form from sources as diverse as the animal rights lobby and the British Toxicology Society. One may therefore hope that testing performed recently includes the careful observation and investigation of effects rather than the simple "corpse count" approach of earlier studies. Some development of methods for the quantitation of sublethal effects has also been undertaken: it is to be hoped that further development in this area will be seen. Studies that are methodologically innovative, or involve compounds of current interest, will be reported in the primary scientific literature. The information other than $L D_{50}$ values for most compounds screened for acute toxicity, however, has not so far appeared in publicly accessible sources. Legislative guidelines now (at least in Britain) refer to the desirability of more complete reporting of acute effects, and propose moderate limits to the required accuracy (and hence animal numbers) and maximum dose for compounds of low toxicity. Unfortunately, the public reporting of these results is still almost entirely confined to the numerical result, or a classification derived from it. Whereas the commercial reasons for seeking confidentiality for the full methodology and results of tests are obvious (if sometimes regrettable), there can be no sound reason for failing to publish in summary form the type of data which have been recommended by the scientific community as being far more useful than a purely numerical $\mathrm{LD}_{50}$ value.

The lack of availability of this additional information is partly historical in origin, since most of the acute toxicity reports data from earlier studies when a numerical result was considered a sufficient conclusion. But to take advantage of the recent changes in experimental design will require a change in approach by regulatory authorities, who sometimes make available data obtained through product registration procedures. This change of attitude will also be necessary for producers of secondary publications and computerised data bases, which are often the only readily available sources of information for those on the spot during an emergency. Within the United Kingdom some of the larger chemical companies have proved helpful in making available data not otherwise accessible, but this enlightened attitude is not universal. It is in any case only a partial solution, and does not benefit everyone, especially in other countries. The special conditions in developing countries should be recognised, and provision made for passing on toxie cological information. Few local centres of expertise currently exist there, but improved access to information and cooperation with scientific centres in the developed countries would enable existing academic and governmental institutions, and international arrangements such as the WHO Collaborating Centres, to function more effectively.

The availability of more complete toxicological information, coupled with a deliberate attempt to remedy past deficiences, would also have beneficial effects in Britain and other developed countries. Possible further improvements in safety systems and procedures might result. The tendency for unnecessary public concern over some well publicised issues (and lack of concern over other problems) would be reduced by wider availability of information. Finally, the quality of research would be enhanced by better underlying information and unnecessary duplication of experiments avoided.

TUC Centenary Institute of Occupational Health, London School of Hygiene and Tropical Medicine, Keppel Street, London WCIE 7HT.

\section{Reference}

Catalog of catastrophe. Time 17 December 1984;13. 